\title{
DC-DC SEPIC CONVERTER TOPOLOGIES
}

\author{
Reeto Jose $K^{1}$, Anisha Shivanandan ${ }^{2}$, Vani Venugopal ${ }^{3}$, Kshemada Devi $\mathbf{V}^{4}$ \\ ${ }^{I} P G$ Student (power electronics), EEE dept., Vidya Academy Of Science And Technology, Kerala, India \\ ${ }^{2} P G$ Student (power electronics), EEE dept., Vidya Academy Of Science And Technology, Kerala, India \\ ${ }^{3} P G$ Student (power electronics), EEE dept., Vidya Academy Of Science And Technology, Kerala, India \\ ${ }^{4}$ PG Student (power electronics), EEE dept., Vidya Academy Of Science And Technology, Kerala, India
}

\begin{abstract}
This paper presents different kind of SEPIC converter Topologies. Those are conventional SEPIC converter, multi resonant SEPIC converter and new resonant SEPIC converter. It is a type of dc-dc converters. It can deliver the output voltage that is less than or larger than the input voltage. It is a fourth order dc-dc converter. Basic operating principle of SEPIC converter is ZVS. MOSFET is used as the switch because of low voltage drop. Conventional SEPIC has two bulk inductors. Multi resonant SEPIC converter needs a resonant capacitor and resonant inductor. The bulk inductor reduces the response speed. The new resonant SEPIC converter has small size, excellent transient performance and higher efficiency. Efficient power conversion can be achieved by switched mode RF inverters like class $E$ inverter. The new resonant SEPIC converter is a dc-dc converter with high frequency and efficiency. New resonant SEPIC converter operating at fixed frequency and duty ratio. It reduces the component count and eliminates the need of bulk inductor. The new resonant SEPIC converter is operating at switching frequency of $20 \mathrm{KHz}$ and converter is simulated by using MAT LAB/SIMULINK for 3.6V input supply.
\end{abstract}

Keywords: conventional SEPIC Converter, Multi resonant SEPIC converter, New resonant SEPIC converter, soft switching

\section{INTRODUCTION}

In high voltage applications, higher voltage rated power semiconductors are used. In order to reduce the volume and weight of the conductors, soft switching techniques such as ZCS and ZVS are necessary. The soft switching operations is increases the system efficiency. Efficient power conversion can be achieved by switched mode RF inverters like class $\mathrm{E}$ inverter. Class $\mathrm{E}$ inverter is commonly used in communication system and the biotelemetry instruments. The SEPIC (Single Ended Primary Inductance Converter) converter has low input current ripple. SEPIC is often used when the desired output voltage can be higher or lower than the input voltage[1]. However, conventional SEPIC designs suffer from substantial switching loss at high frequency, slow response speed, poor load step performance or all of the above performance deficiencies. These drawbacks can be reduced by Resonant SEPIC converter by offering large operating range, small size and acceptable performance. Here introducing a new quasi-resonant SEPIC topology that maintains ZVS characteristic across wide output and input voltage range provides excellent dynamic performance, while keeping minimal energy storage requirement and low component count[2]. SEPIC converters are mainly used for industrial applications such as power factor correction, photovoltaic system and LED lighting. Unlike conventional and multi resonant converters no bulk inductor is used in the new resonant SEPIC converter.This converter operates at fixed switching frequency and duty ratio. These characteristics improve response speed, reduce passive component size, and allow the use of low-loss sinusoidal resonant gating [4].

\section{CONVENTIONAL SEPIC CONVERTER}

The SEPIC converter exchanges energy from the capacitor and inductors for converting voltage to another voltage. The conventional SEPIC converter as shown in fig 1.It has two bulk inductors and produces hard switching of the switch and diode. The switch $\mathrm{S}_{1}$ control the sum of energy exchanged. MOSFET has lower voltage drop than BJT ,higher input impedance and it does not require biasing resistor.Switching is controlled by voltage difference relatively than a current as BJTs.

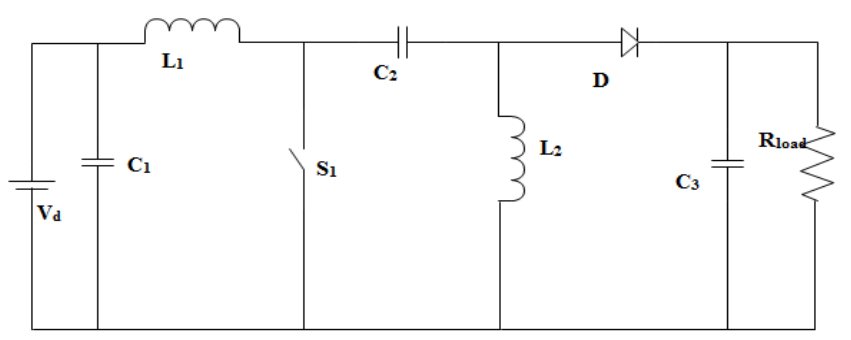

Fig-1:Conventional SEPIC Converter

When switch $S_{1}$ is $O N, I_{L 1}$ increases. $I_{L 2}$ increases in the opposite (negative) direction. The current through $\mathrm{I}_{\mathrm{L} 1}$ increase from the input source $\mathrm{V}_{\mathrm{d}}$. The instantaneous voltage $\mathrm{V}_{\mathrm{c} 2}$ is nearly equal to $\mathrm{V}_{\mathrm{d}}$, the voltage $\mathrm{V}_{\mathrm{L} 2}$ is nearly equal to $-V_{d}$. Therefore the capacitor $C_{2}$ delivered to increase the energy stored and the magnitude of energy in the $\mathrm{I}_{\mathrm{L} 2}$. When switch $S_{1}$ is closed the current increases through $L_{1}$ and the capacitor discharges through $\mathrm{L}_{2}$. 
When switch $S_{1}$ is OFF, the current $I_{c 2}=I_{L 1}$, since the inductor does not allow instantaneous changes in current. The $I_{L 2}$ is in the negative directions, because it never reverses direction.

$$
I_{D}=I_{c 2}-I_{L 2}
$$

The power is delivered to the load from both $\mathrm{L}_{1}$ and $\mathrm{L}_{2}$ when $S_{1}$ is OFF $C_{2}$ is being charged by $L_{1}$ during the OFF cycle and to charging the $\mathrm{L}_{2}$ during the $\mathrm{ON}$ cycle. Because the voltage across capacitor $\mathrm{C}_{2}$ reverse direction in every cycle. Reducing the effects of the internal resistance and parasitic inductance of the power supply by using the capacitor $\mathrm{C}_{1}$.

\section{Limitations of Conventional SEPIC Converter}

1. Conventional SEPIC designs suffer from substantial switching loss at high frequency, slow response speed, poor load step performance and a pulsating output current.

2. SEPIC converter transfers all its energy through the series capacitor.so the capacitor have high current handling capability and capacitance is required.

3. Bulk inductors are used in conventional SEPIC. That increases the component sizing and reduces the response speed.

\section{MULTI RESONANT SEPIC CONVERTER}

The fig 2 shows multi resonant SEPIC converter.In this topology capacitance parallel with the switches and the diodes along with the resonant inductor $\left(\mathrm{L}_{\mathrm{s}}\right)$ in series with the coupling capacitor $\left(C_{2}\right)$ to achieve the zero voltage switching of the diode and switch [3]. It maintains the good efficiency as the load condition changes by using the frequency modulation control in the power stage and the control function. Like conventional SEPIC Converter, the bulk inductor limit the response speed of the multi resonant SEPIC Converter.

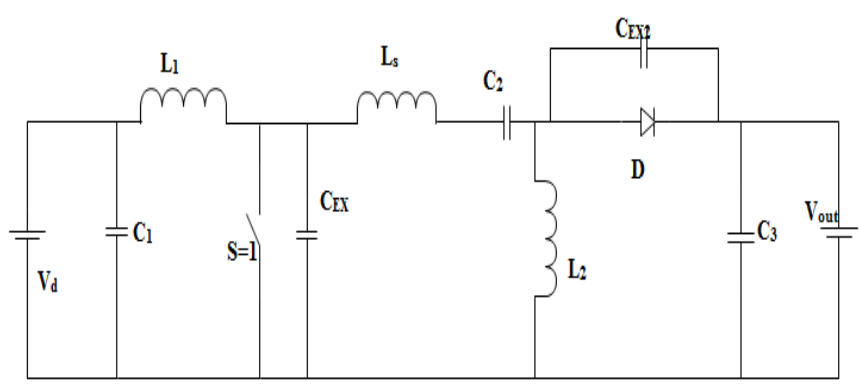

Fig-2:Multi Resonant SEPIC Converter

\section{NEW RESONANT SEPIC CONVERTER}

Conventional SEPIC converter, a large amount of output bulk capacitance is needed. This translates to large size, deteriorate power density and higher cost. In resonant SEPIC converter use two resonant inductors. One inductor $\mathrm{L}_{1}$ resonates with the net switching capacitance $\mathrm{C}_{\mathrm{EX}}+\mathrm{C}_{2}$, for resonant inversion[1]. $\mathrm{L}_{2}$ is resonate with the rectifier capacitance. $\mathrm{C}_{\mathrm{EX} 2}$ for resonant rectification. This design methods leads to reduced magnetic component count and increases response speed. Here operation at fixed frequency and duty ratio allows the elimination of bulk magnetic components and reduces the device stress.

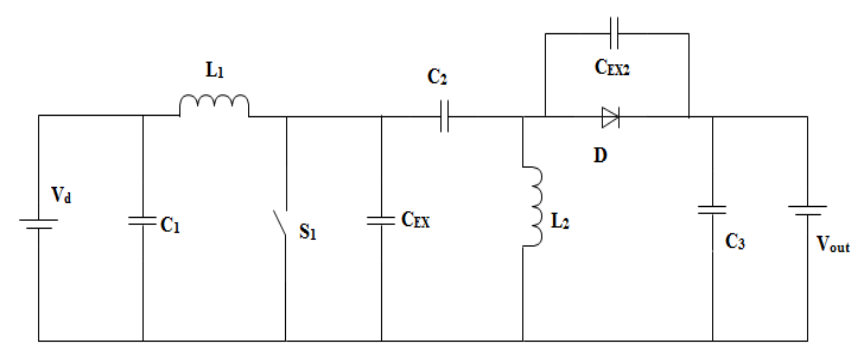

Fig-3:New Resonant SEPIC Converter

\section{Two sub system}

Resonant SEPIC converter consist of two subsystem.

1) Resonant inverter

2) Resonant rectifier

\subsection{Resonant Rectifier}

There is a resonant tank circuit, it consists of resonant inductor $\left(\mathrm{L}_{2}\right)$ and capacitance $\left(\mathrm{C}_{\mathrm{EX} 2}\right)$.It is an additional parasitic junction capacitance from the diode.

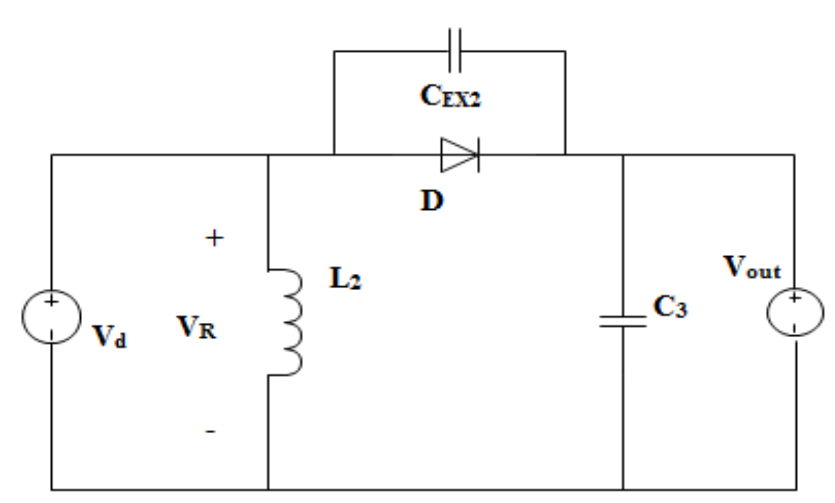

Fig -4: Resonant Rectifier

When diode off , $\mathrm{L}_{2}$ and $\mathrm{C}_{\mathrm{EX} 2}+$ junction capacitance resonate until the $\mathrm{V}_{\mathrm{R}}$ reaches the $\mathrm{V}_{\text {out }}$. At turn off , the voltage across the capacitor equal to $V_{\text {out }}$ and $I_{L 2}$ start decreasing. $V_{R}$ is being discharged until the inductor current is lower than the driving current source. Once this condition is reached, $\mathrm{I}_{\mathrm{L} 2}$ continuous to decrease, the capacitor $\mathrm{C}_{\mathrm{EX} 2}$ start absorbing energy and $V_{R}$ rings up. Once $V_{R}$ reaches $V_{\text {out }}$, the diode again turn on and the inductor current increases until it exceeds the driving current,then the diode off and cycle repeats . 


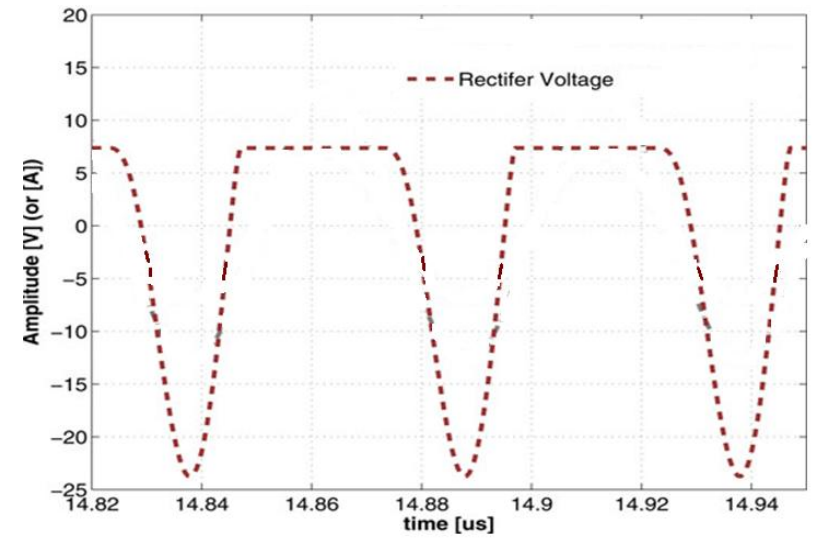

Fig -5: Resonant Rectifier Voltage

\subsection{Resonant inverter}

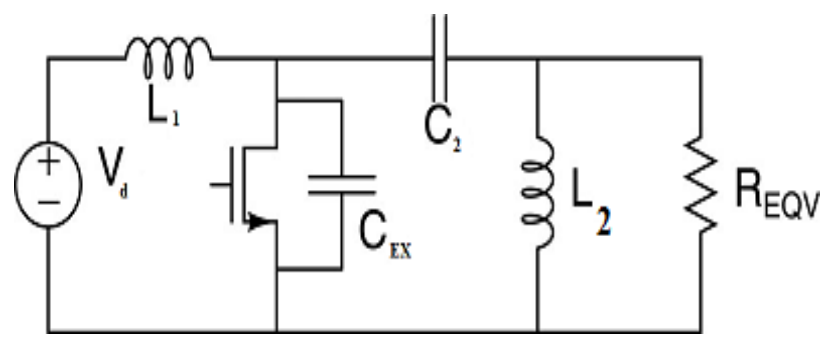

Fig -6: Resonant Inverter

When switch off, the voltage at the drain of the device $V_{d}$ rises, the current in the inductor $\mathrm{L}_{1}$ increases the capacitor in parallel to the switch $\mathrm{C}_{\mathrm{EX}}$ being charged as shown in fig 6.The voltage at the drain continuous to rise until the current in the $C_{E X}$ is zero.Then $V_{D S}$ goes to negative value.As the voltage of drain rings down to zero from it's peak value, the current in $\mathrm{C}_{\mathrm{EX}}$ down to zero at which point the switch turn on. When switch on, $\mathrm{C}_{\mathrm{EX}}$ is now replaced by the short circuit.During this interval the current in resonant inductor $\mathrm{L}_{1}$ continuous to increases, the energy flows from input voltage and is stored in $\mathrm{L}_{1}$. The value of inductor $\left(\mathrm{L}_{1}\right)$ is small.

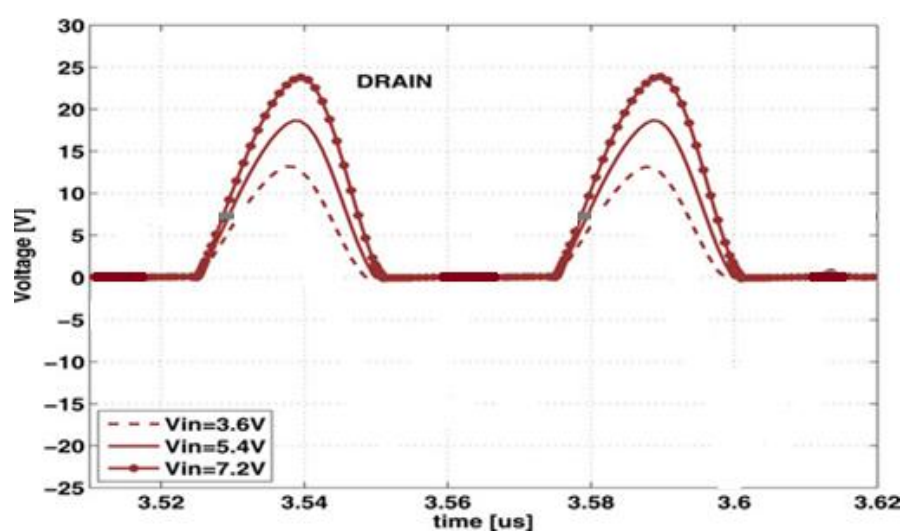

Fig -7: Drain Voltage

\section{SIMULATION RESULTS}

Simulation result for resonant rectifier and resonant inverter. $\mathrm{V}_{\mathrm{in}}=3.6 \mathrm{~V}, \mathrm{~L}_{1}=\mathrm{L}_{2}=\mathrm{L}_{\mathrm{R}}=648 \mu \mathrm{F}, \mathrm{C}_{\mathrm{EX}}=\mathrm{C}_{\mathrm{EX} 2}=3.2 \mathrm{pF}, \mathrm{C}_{3}=\mathrm{C}_{2}=20 \mathrm{nF}$

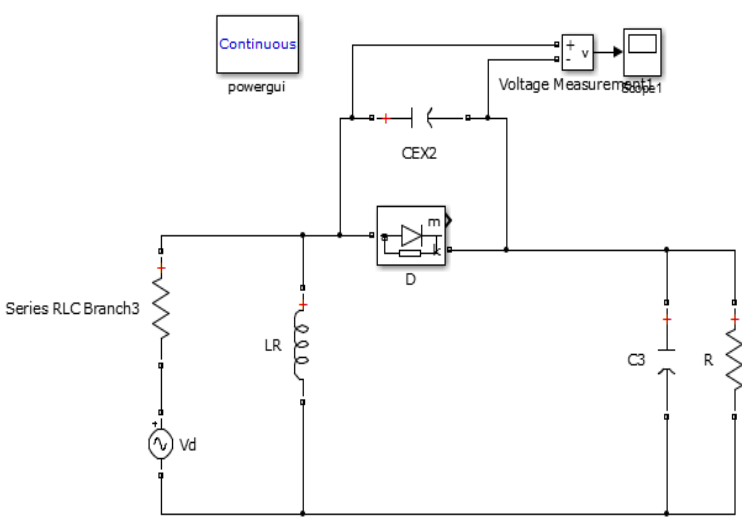

Fig -8: Simulation Of Resonant Rectifier

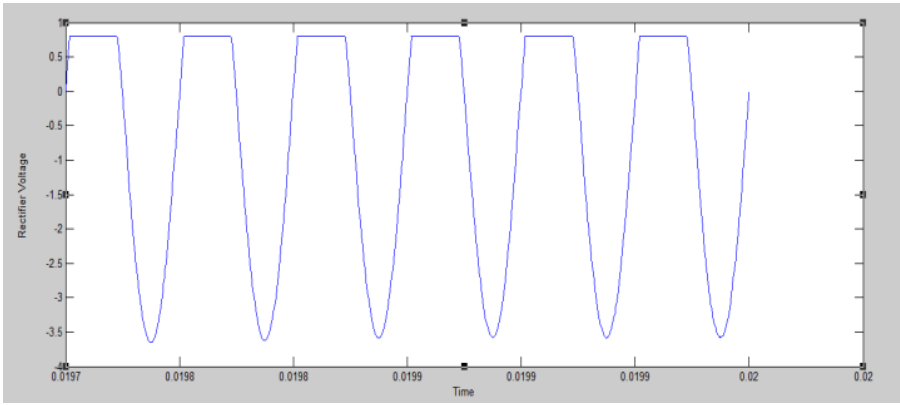

Fig -9: Simulated Wave Form For Resonant Rectifier Voltage

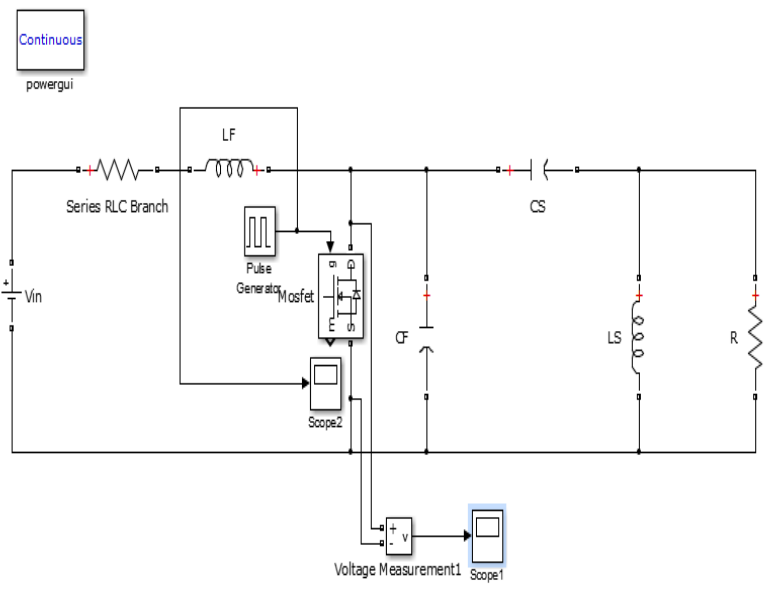

Fig -10: Simulation Of Resonant Inverter

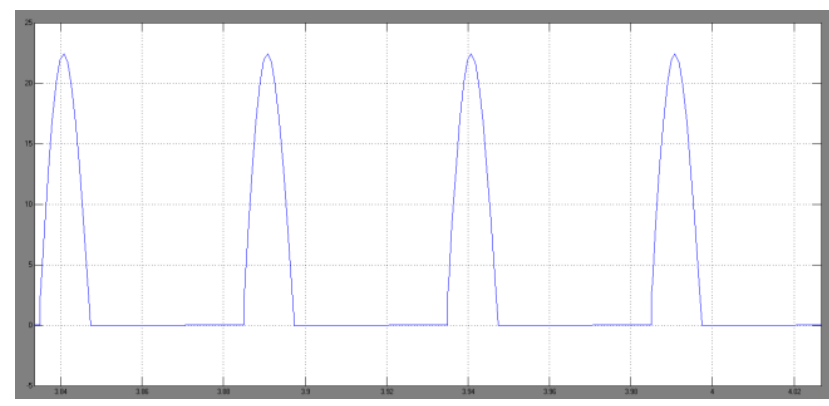

Fig -11: Simulated Wave Form For Drain Voltage 


\section{CONCLUSION}

The conventional SEPIC converter need capacitance with high value and high current handling capacity. The bulk inductor is used in conventional SEPIC converter,so it is increases the component size and reduces the response speed. Like conventional SEPIC Converter,the bulk inductor limit the response speed of the multi resonant SEPIC Converter. Unlike the conventional SEPIC converter, new resonant SEPIC converter no bulk inductor are used and operating at fixed frequency and the duty ratio. These characteristics reduce passive component size, improve response speed. Soft switching can be achieved for a wide input and output voltage ranges. Simulated the new resonant SEPIC converter using MATLAB/Simulink for 3.6V.

\section{REFERENCES}

[1]. Sweta Srivastav, Sanjay Kumar Singh, An introduction to Resonant SEPIC converters with variable Input and Output conditions International Referred Research Journal,September ,2011, VOL-II

[2]. Jingying $\mathrm{Hu}$, Student Member, IEEE, Anthony D. Sagneri, Student Member,IEEE, Juan M. Rivas, Member, IEEE, Yehui Han, Member, IEEE, Seth M. Davis, and David J. Perreault, Senior Member, IEEE "High-Frequency Resonant SEPIC Converter With Wide Input and Output Voltage Ranges" IEEE Transaction on power electronics.vol.27,no.1,january 2012.

[3]. J. Hu, Design of a low-voltage low-power dc-dc hf converter, M.S. thesis, Dept. Elect. Eng. Comput.Sci.,Massachusetts Institute of Technology (MIT), Cambridge, 2008.

[4]. R. C. Pilawa-Podgurski, A. D. Sagneri, J. M. Rivas, D. I. Anderson, and D. J. Perreault, "Very high frequency resonant boost converters," in Proc. Power Electron. Spec. Conf., Jun. 2007, pp. 2718-2724.

\section{BIOGRAPHIES}

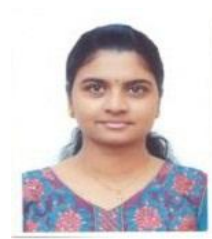

Reeto Jose $\mathbf{K}$ received B.Tech in electrical and electronics engineering from university of Calicut in 2013.She is currently PG student in power electronics with the department of EEE from university of calicut.

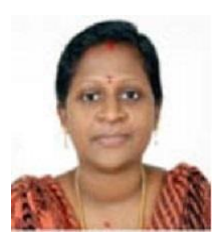

Anisha Shivanandan received B.Tech in electrical and electronics engineering from university of Calicut in 2009.She is currently PG student in power electronics with the department of EEE from university of calicut.

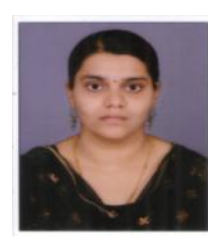

Vani Venugopal received B.Tech in electrical and electronics engineering from university of Calicut in 2012.She is currently PG student in power electronics with the department of EEE from university of calicut..

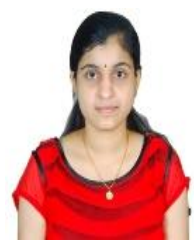

Kshemada Devi V received B.Tech in electrical and electronics engineering from university of Calicut in 2012.She is currently PG student in power electronics with the department of EEE from university of calicut. 